\title{
CBCT Assessment of Dental and Skeletal Changes Using the Damon versus Conventional (MBT) System
}

\author{
Marjan Askari ${ }^{1,2}$, Robert Williams ${ }^{3}$, Elaine Romberg ${ }^{4}$, Maureen Stone ${ }^{5}$ and Stanley A Alexander ${ }^{6,7 *}$ \\ ${ }^{1}$ Assistant Clinical Professor, Department of Pediatric Dentistry, School of Dental Medicine, Tufts University, Massachusetts, United States \\ ${ }^{2}$ Director of Orthodontics, Holyoke Health Center, Holyoke, Massachusetts, United States \\ ${ }^{3}$ Clinical Assistant Professor of Orthodontics, School of Dentistry, University of Maryland, Maryland, United States \\ ${ }^{4}$ Professor of Endodontics, School of Dentistry, University of Maryland, Maryland, United States \\ ${ }^{5}$ Professor of Neural and Pain Sciences, School of Dentistry, University of Maryland, Maryland, United States \\ ${ }^{6}$ Chief Dental Officer, Holyoke Health Center, Holyoke, Massachusetts, United States \\ ${ }^{7}$ Distinguished Teaching Professor Emeritus, Stony Brook University, Stony Brook, New York, United States
}

\begin{abstract}
Introduction: The primary aim of this pilot study was to compare cases treated with the Damon System and a Conventional Mechanics system utilizing Cone Beam Computed Tomography (CBCT) in the evaluation of changes in dental and skeletal arch width and length. The secondary purpose was to evaluate differences between the three CBCT views (3-D coordinate, sectional, and volume views).
\end{abstract}

Methods: Eleven patients ( $\geq 18$ years of age; measured total of 40 maxillary antimeres and 44 mandibular antimeres) with moderate to severe crowding who had both pre and post-treatment CBCTs and were treated nonextraction, either with conventional edgewise or self-ligating Damon appliances were retrospectively selected from two orthodontic practices. The arch length, inter-occlusal, inter-apical, inter-buccal and inter-lingual alveolar crest arch widths and the bucco-lingual angulation for canine, premolars and first molars were measured. Different CBCT views were evaluated by first measuring the inter-occlusal distances of the respective teeth in the coronal section and the volume views. These measurements were compared with those gathered previously using the 3-D coordinate system. A paired t-test, an independent t-test, and an ANOVA were used for statistical analysis.

Results: Both non-extraction treatment modalities resulted in inter-occlusal arch width expansion in both the maxilla and mandible. The overall expansion of arches in the Damon treated cases was statistically greater than in the Conventional cases. Maxillary and mandibular arch lengths were increased, but not significantly in both groups. There were no statistically significant differences between the three CBCT views.

Conclusions: Both the Damon and the Conventional systems resulted in increased arch width and length, but the Damon system caused significantly more overall arch expansion. There was less tipping of the teeth during arch expansion in the Conventional system. The ratio of crown to root movement in the Conventional system versus the Damon system in the maxilla was approximately $1: 1$ versus $3: 1$, and in the mandible $3.6: 1$ versus $6: 1$, respectively.

\section{Keywords: CBCT; Class I malocclusions; Damon system}

\section{Introduction}

The evolution of the shape of the human dental arch is distinct when compared to other primates, while hominid evolution has demonstrated that the arch form in man is parabolic [1]. For over 100 years the size and shape of the ideal dental arch has been used for diagnosis and treatment of malocclusions and two diverging methods of therapy: extraction versus non-extraction. Proponents of non-extraction treatment have indicated that extractions result in a detrimental result in profile and smile esthetics, large buccal corridors and faulty final occlusions. Recent reports indicate that extraction therapy does not negatively impact on soft tissue [2,3], nor does it negatively affect smile esthetics [4-6]. If the current state of evidence points in the direction that extraction therapy has no detrimental effect in facial esthetics and provides a superior occlusion to non-extraction treatment, one would expect a greater predominance of patients treated with the extraction of teeth to successfully resolve their malocclusions. However, with the advent of the Damon philosophy and through the use of self-ligation with low force, low friction arch wires, the pathway to non-extraction treatment has been resurrected and gaining favor in orthodontic therapy.

Opposition to non-extraction therapy was largely based on the retention period where relapse of crowding was due to lateral expansion of the arches and proclination of the incisors [7]. The treatment of Class I malocclusions without extraction irrespective of the treatment modality resulted in a generalized expansion of the buccal segments along with the advancement of the lower incisors, and found that expansion was greatest at the second premolars and least at the canines [8]. Other studies using a single type of expansion appliance (rapid palatal expansion, quad-helix, lip bumper, or tandem mechanics) all resulted in a greater mean change in mandibular arch width [9-12].

The Damon system was first introduced in the 1990s and incorporates low friction and low force wire technology with the use of passive self-ligating brackets. The general philosophy underlying this system is to approximate biologically induced tooth moving forces that results in the alteration of the arch form. The new arch form is adapted from the basic arch form and is "physiologically determined", while creating a new equilibrium that allows the arch to reshape itself

*Corresponding author: Stanley A Alexander, DMD, Chief Dental Officer, Holyoke Health Center, 230 Maple Street, Holyoke, MA 01041, United States, Tel: 413-4206257; E-mail: stanalexander427@gmail.com

Received July 22, 2015; Accepted September 03, 2015; Published September 13, 2015

Citation: Askari M, Williams R, Romberg E, Stone M, Alexander SA (2015) CBCT Assessment of Dental and Skeletal Changes Using the Damon versus Conventional (MBT) System. Dentistry 5: 336. doi:10.4172/2161-1122.1000336

Copyright: ( 2015 Askari M, et al. This is an open-access article distributed under the terms of the Creative Commons Attribution License, which permits unrestricted use, distribution, and reproduction in any medium, provided the original author and source are credited. 
to accommodate the full complement of teeth $[13,14]$. Treatment protocols using the Damon system have attempted to mirror biological and physiological principles of tooth movement with the use of light arch wires that do not overpower lip musculature, thereby producing a lip bumper effect on the maxillary and mandibular incisors. According to Damon principles, the teeth take on the path of least resistance which in extraction cases means teeth move into the extraction site; however in non-extraction therapy, this treatment philosophy purports posterior expansion with maintenance of the incisor anteroposterior position $[13,14]$. This statement has been disputed by various studies that have indicated we know very little from the early Damon study of photographs of 'great smiles', and that this philosophy of care results in an increase in both arch length, interbicuspid width, forward movement of the lip, and proclination of the incisors [15-17].

Study casts and lateral cephalograms have been used to evaluate arch expansion and incisor proclination for both conventional and selfligating systems. Images obtained by cone beam computer tomography (CBCT) provides an undistorted view of tooth roots and 3-D spatial orientation of both bones and teeth [18]; this technology can be utilized to evaluate the effects of treatment on the crown, roots and alveolar bone of individual patients.

The purpose of this investigation therefore, was fourfold:

- to evaluate the changes in arch dimensions of non-extraction treated cases using CBCT;

- to evaluate the changes in dental and skeletal arch width and length in patients treated with the Damon System;

- to evaluate the changes in dental and skeletal arch width and length in patients treated with conventional mechanics, and

- to evaluate the differences in the dental and skeletal arch width and length measurements of patients treated with the Damon System when compared to patients treated with Conventional mechanics.

\section{Method and Materials}

Approval to conduct this study was obtained from the Human Research Protections Office (HRPO) of the University of Maryland Institutional Review Board. Patients were retrospectively selected from the offices of two private practices, one office that exclusively utilized a self-ligating Damon system and the second office that utilized a conventional edgewise system with an MBT prescription. Both systems used 0.022-in archwire slots. Patients with moderate $(3-6 \mathrm{~mm})$ to severe $(>6 \mathrm{~mm})$ crowding as judged by the clinicians were utilized. Eleven subjects were selected in this study based on the following:

\section{Inclusion criteria}

- Patients having an age of 18 years or older

- Class I occlusion or mild class II/III malocclusion

- Moderate to severe crowding

- Non-extraction treatment

- No interproximal reduction

- No therapeutic intervention exclusive of arch wires

- No surgical intervention

- Available initial and final CBCT

- No missing teeth, excluding second and third molars

\section{Exclusion criteria}

- Patients prior to pubertal growth

- Extraction at any point during treatment

- Missing teeth, excluding second or third molars

- Pathology associated with head and neck area

- Radiation to the head and neck area

Five patients who received treatment of both the maxillary and mandibular arches in both treatment groups (Damon and Conventional MBT), and one patient in the Damon group with only the mandibular arch fitting the criteria were included in the study for a total of 40 maxillary antimeres and 44 mandibular antimeres measured. Both treatment groups were equally composed of patients with crowding ranging from both the 3-6 $\mathrm{mm}$ and greater than $6 \mathrm{~mm}$ levels and with ovoid arch forms. Cephalometrically, all eleven patients presented with Class I skeletal relationships (Wits appraisal $=$ to $-1 \mathrm{~mm}$ to $+1 \mathrm{~mm}$ and ANB relationships of $+1^{\circ}-3^{\circ}$ ), Class I (Angle) dental relationships, normal mandibular plane angles ranging from $29^{\circ}-32^{\circ}$, and normal vertical proportions. Mandibular incisor positions ranged from $88^{\circ}-97^{\circ}$ to the mandibular plane, while the maxillary incisor positions to the sella-nasion plane ranged from $105^{\circ}-112^{\circ}$.

In the group treated with the Conventional edgewise system, the brackets used were $3 \mathrm{M}$ Unitek APC with MBT prescription $(0.022$ slot). The treating orthodontist used the following arch wire sequence (ovoid arch form, 3M Unitek Corp.) that was ligated with elastomeric ligation:

\section{Maxilla/Mandible}

- 0.014 to 0.016 inch nickel-titanium

- 0.018 inch stainless steel

- $0.016 \times 0.022$ inch nickel-titanium

- $0.019 \times 0.025$ inch stainless steel

The final arch wires were customized to the individual patient's arch form.

In the group treated with the Damon appliance (Ormco Corp.), Damon Q Standard, self-ligating brackets were utilized. The following arch wires (Damon Arch; Ormco Corp.) were sequentially used:

\section{Maxilla}

- 0.014 to 0.016 inch copper nickel-titanium

- $0.016 \times 0.025$ inch copper nickel-titanium

- $0.018 \times 0.025$ inch copper nickel-titanium

- $0.019 \times 0.025$ inch stainless steel

The final arch wire was customized to the individual patient's arch from.

\section{Mandible}

- 0.014 to 0.016 inch copper nickel-titanium

- 0.014 x 0.025 inch copper nickel-titanium

- $0.018 \times 0.025$ copper nickel-titanium

- $0.016 \times 0.025$ inch stainless steel 
The final arch wire was customized to the individual patient's arch

Each arch wire placement, on average, was for a 4-5 month period for each treatment group for an average treatment time of 17-20 months.

Both the Conventional and Damon treated cases were scanned in an i-Cat machine (Imaging Sciences). DICOM files were obtained via the i-Cat machine with 0.3 voxel resolution. The Anatomage Invivo Dental 5.0 volumetric imaging software was used for all measurements used in the study.

Since all CBCTs were obtained with patients in centric occlusion, the non-functional cusps in each arch were used to measure the inter-occlusal arch width for better cusp tip view. The arch width was measured at the first molar, first and second premolars, and the cuspids in both arches. The arch width measurements included not only the occlusal portions of the teeth, but also their respective buccal and lingual cortical plates. The inter-apical areas of each of the respective teeth were also measured along with the angulations of each tooth. Arch length was measured as the distance between the mid-point of the line connecting the mesial of the first molars to the contact point between the central incisors. Arch width, arch length, and tooth angulation were measured at pre-treatment, $\mathrm{T}_{1}$ and post-treatment, $\mathrm{T}_{2}$.

A clear view of the object being measured was obtained using in vivo tools. Two 3rd year dental students who were trained to work with the software, but were blind to the study recorded pictures and data for each patient. Both dental students worked together for all measurements for all of the patients and consulted with each other as to the optimal placement of reference points on every measurement taken as well as what constituted the most accurate view. Table 1 indicates the measurements that were obtained on the frontal section view after the image was coordinated in the sagittal and coronal views as seen in Figure 1, unless otherwise stated. The red dots indicate points of interest, blue lines show the distance between the two points, the green numbers indicate the actual measurements, and the other two lines (green and orange line) are to coordinate the views.

Conventional lateral cephalograms compared to $\mathrm{CBCT}$ were taken with teeth in occlusion. The segmentation (separation) of maxillary and mandibular teeth becomes more difficult because the cusps of antagonist teeth overlap. Teeth in occlusion scans make it more difficult to build an accurate dental model as they reduce the visibility of teeth surfaces [19]. Since the CBCTs of patients in this study were taken with patients in centric occlusion, the non-functional cusps were chosen for interocclusal arch width and angular measurements.

\section{Dental measurements}

Arch width; Inter-occlusal (IOD) and Inter-Apical (IAD) Distances: Individual arch width measurements of paired teeth were made from cusp tip to cusp tip. The non-functional cusps were chosen except for mandibular first premolars. Combined IOD differences for canines, premolars and molars were also made in each arch for statistical purposes (Table 1).

Canines: Interocclusal arch width for canines was measured from cusp tip to cusp tip; inter-apical distance was measured from apex to apex.

Premolars: Interocclusal arch width for maxillary premolars and mandibular second premolars was measured between non-functional cusp tips; however, the inter-occlusal arch width for the mandibular first premolars wre measured from the functional cusps due to rudimentary lingual cusps of these teeth. Inter-apical distance was measured from premolar apex to apex. When two roots were present, the buccal root apex was chosen. The first and second premolars were measured separately and then combined for all measurements for statistical purposes.

Molars: The inter-occlusal arch width was measured in two different ways. One measurement was made from the central fossa to central fossa. This measurement is less affected by tipping of these teeth than if the cusp tips were chosen. The second measurement was made

\begin{tabular}{|c|c|}
\hline Measurements & Definition \\
\hline Arch Length $(\mathrm{AL})$ & Perpendicular distance from line connecting the mesial of $1^{\text {st }}$ molars to the contact point between central incisors \\
\hline \multicolumn{2}{|r|}{ Arch Width } \\
\hline Inter-occlusal dimension (IOD) & $\begin{array}{l}\text { - K9: Distance between canine cusp tips } \\
\text { - Mand PM1: Distance between mandibular } 1^{\text {st }} \text { premolars buccal cusp tips } \\
\text { - Mand PM2: Distance between mandibular } 2^{\text {nd }} \text { premolars lingual cusp tips } \\
\text { - Max PMs: Distance between maxillary premolars buccal cusp tips } \\
\text { - Mand M1: Distance between mandibular } 1^{\text {st }} \text { molar lingual grooves } \\
\text { - Max M1: Distance between maxillary } 1^{\text {st }} \text { molar buccal grooves }\end{array}$ \\
\hline Inter-central-fossa (ICF) & M1: distance between $1^{\text {st }}$ molars' central fossae \\
\hline Inter-apical dimension (IAD) & $\begin{array}{l}\text { - K9: Distance between canine apices } \\
\text { - Mand PMs: Distance between mandibular premolar apices } \\
\text { - Max PMs: Distance between maxillary premolar apices } \\
\text { - Mand M1: Distance between mandibular } 1^{\text {st }} \text { molar mesial root apices } \\
\text { - Max M1: Distance between maxillary } 1^{\text {st }} \text { molar palatal root apices }\end{array}$ \\
\hline Inter-buccal alveolar crest dimension (IBACD) & Distance between buccal alveolar crestal bone \\
\hline Inter-lingual alveolar crest dimension (ILACD) & Distance between lingual alveolar crestal bone \\
\hline \multicolumn{2}{|r|}{ Tooth Angulation } \\
\hline Tooth Angulation & $\begin{array}{l}\text { Angulation of the tooth on the right/left side (R/L-angle) } \\
\text { - Mand canine: Angle between cusp tip to apex to mandibular border } \\
\text { - Max canine: Angle between cusp tip to apex to nasal floor } \\
\text { - Mand PM1: Angle between buccal cusp to apex to mandibular border } \\
\text { - Mand PM2: Angle between lingual cusp to apex to mandibular border } \\
\text { - Max PMs: Angle between buccal cusp to palatal root apex to nasal floor } \\
\text { - Mand } 1^{\text {st }} \mathrm{M} \text { : angle between central fossa to furcation to mandibular border } \\
\text { - Max } 1^{\text {st }} \mathrm{M} \text { : angle between central fossa to furcation to nasal floor }\end{array}$ \\
\hline
\end{tabular}

Table 1: Measurements and abbreviations used for the description of arch length, arch width, and tooth angulation. 


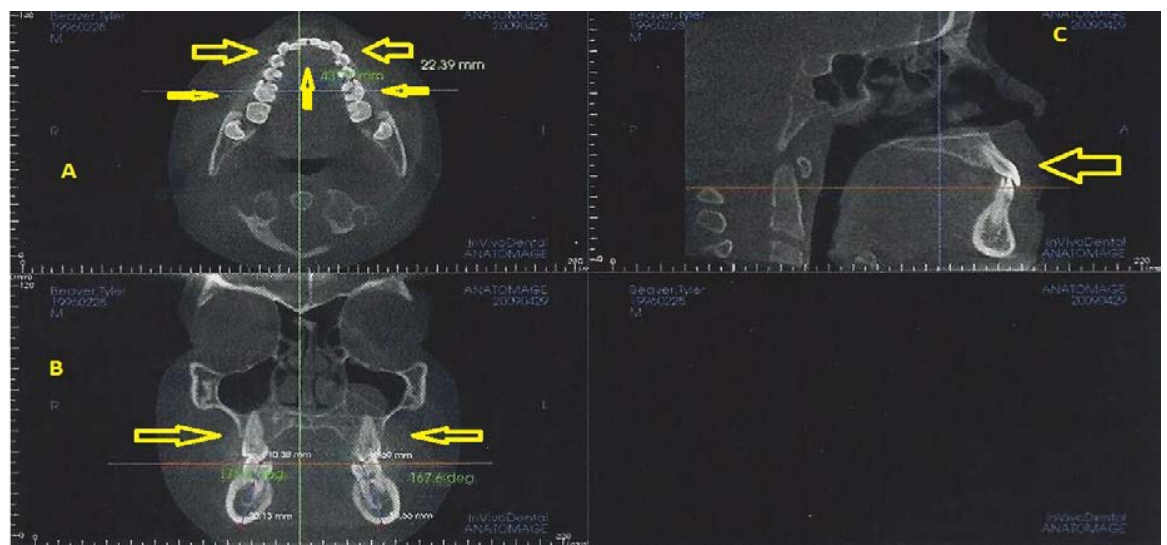

A. Occlusal view, horizontal arrows indicate arch width expansion measurements of the buccal segments; vertical arrow indicates arch length;

B. Coronal view, arrows indicate angular change measurements as a result of expansion of the dental arches;

C. Lateral view, arrow indicates angular position of the incisors (not measured in this study).

Figure 1: An example of a 3-D Coordinate System of a subject's CBCT scan.

between the non-functional cusps after first coordinating the points in the coronal view. The non-functional cusp/groove in the frontal view was chosen.

To measure the inter-apical distance in the mandible, the mesial root apices were selected by scanning through sectional slices in the frontal view until first molar root apices on either side of each arch were visible. For maxillary first molars, the inter-apical distance of the palatal roots were chosen.

\section{Angular measurements}

The angulations of the maxillary teeth were all measured relative to the point of intersection between the nasal septum and the nasal floor as was seen in the frontal view. The angulation of the mandibular teeth was measured relative to the lowest border of the mandible in the frontal view. Angulations were measured separately on each tooth for the right $(\mathrm{R})$ and left $(\mathrm{L})$ side, but the combined $\mathrm{R}$ and $\mathrm{L}$ for each tooth is reported for statistical purposes.

Maxillary canine: Angle between cusp tip to apex to nasal floor.

Mandibular canine: Angle between cusp tip to apex to the lower border of mandible.

Premolars: The non-functional cusp tips to apex to nasal floor in maxilla and to the lowest border of the mandible. Functional cusps were chosen for the mandibular first premolars as a source of measurement. If there were two premolar roots available, the buccal root was chosen.

Molars: The central fossa to furcation to nasal floor or lowest border of the mandible.

\section{Skeletal arch width measurements}

The skeletal arch width measurements for each of the teeth included the distance between the alveolar bone and the respective tooth to the same point on the other side of the arch.

- $\quad \mathrm{IBACD}=$ buccal crest of bone to buccal crest of bone

- $\quad$ ILACD = lingual crest of bone to lingual crest of bone

\section{Arch length}

The arch length was measured as a perpendicular distance from a line connecting the mesial of the first molars to the contact between the central incisors. The maxillary arch lengths were measured in the volume view, whereas the mandibular measurements were done in the section view.

\section{Inter-occlusal arch width measurements}

The same data was also gathered for individual teeth using the 3-D coordinate system for better visualization of individual teeth to be measured. The measurements of the inter-occlusal arch width distances were obtained using the section and volume views for all teeth as if looking at a dental cast from the occlusal. This was done to compare the relative accuracy of these views as opposed to the previously measured inter-occlusal distances of the respective teeth using the three coordinate systems. This view helps to identify the most exact point of interest since you have the option of manipulating the section view in the frontal, sagittal and coronal coordinate system before the actual measurement is obtained.

\section{Maxilla}

- from cusp tip to cusp tip of canine

- from buccal cusp tip to buccal cusp tip of $1^{\text {st }}$ and $2^{\text {nd }}$ premolar

- from buccal groove to buccal groove of $1^{\text {st }}$ molar

\section{Mandible}

- from cusp tip to cusp tip of canine

- from lingual cusp tip to lingual cusp tip of $1^{\text {st }}$ and $2^{\text {nd }}$ premolar

- from lingual groove to lingual groove of $1^{\text {st }}$ molar

\section{Assessment methods}

In order to evaluate the effect of each treatment separately, changes in the inter-occlusal arch dimension (IOD), inter-apical arch dimension (IAD), and the arch length (AL) were compared. For comparison of the dental and skeletal differences between the Damon and Conventional systems, differences between the pre- and posttreatment arch width and arch length in each treatment group were measured. For evaluation of the translation of the alveolus laterally, the pre- and post-treatment dimensional changes in buccal (IBACD) and lingual (ILACD) plates were compared. To evaluate the axial tipping 
of teeth, the pre- and post-treatment measurements of IOD and IAD changes and the changes in angular dimension were determined. Finally, to evaluate the accuracy of the different views using CBCT, readings on inter-occlusal arch dimensions were compared among the three views: the section view for all involved teeth, the volume view with arches handled like dental casts, and the individual measurements obtained via a 3-D coordinate system.

\section{Statistical analysis}

For the assessment of error, several CBCTs of patients were randomly selected and re-measured. Systematic errors were estimated by using a paired 2-tailed t-test; no significant differences were found. Dahlberg's formula [20] was used for calculation of combined method Dahlberg's Formula $=\sqrt{ } \Sigma \mathrm{d}^{2} / 2 \mathrm{n}$ errors in locating and measuring different landmarks:

where $d$ is the difference between the two measurements of a pair, and $\mathrm{n}$ is the number of double measurements.

Since in this study the points of interest were located at different spatial orientations and clinically some harder to locate than others, Dahlberg's calculation was performed on duplicated measurements with regard to their degree of difficulty. In case of very difficult measurements (i.e. maxillary teeth angulation), 15 calculations were performed on random cases. The same calculations were performed for four moderately difficult points (IBACD, ILACD) and four easy points (IOD, IAD).

To evaluate changes within each treatment category (Damon or Conventional), a paired t-test was used; to evaluate dental and skeletal changes between different treatment groups, an independent t-test was performed on the differences between initial and final measurements in each treatment category; to evaluate significant difference between different views of CBCT, one-way ANOVA was used.

\section{Results}

In this study method errors were $0.053 \mathrm{~mm}$ for easy points to identify, $0.63 \mathrm{~mm}$ for moderately difficult measurement points, and $5.3^{\circ}$ for difficult angular measurements. This data is in agreement with the findings of Damstra et al. [21].

\section{Damon cases}

In order to examine the changes from the initial readings to the final readings of Damon treated cases, a paired t-test was performed for each respective tooth's IOD, ICF, IAD, and arch length.

Maxilla: All inter-occlusal arch width differences for the measured teeth (K9, PM1, PM2, and M1) increased during treatment (Table 2). However, statistically significant differences were observed only for the cuspids ( $\mathrm{p}=0.024)$ and the first and second premolars ( $P M 1, \mathrm{p}=0.021$; $\mathrm{PM}$ 2, $\mathrm{p}=0.032)$. The inter-central fossa distance between the first molars increased to a statistically significant degree (M1-ICF, $\mathrm{p}=0.026$ ). However, the first molars inter-occlusal change, when measured at the non-functional cusps did not show a significant difference. Inter-apical distances of all measured teeth decreased, but the changes were not statistically significant, while the arch length increase during treatment approached statistical significance $(\mathrm{p}=0.078)$.

Mandible: All inter-occlusal arch width differences increased to a statistically significant degree, (Table 3$)(\mathrm{K} 9, \mathrm{p}=0.04$; PM1, $\mathrm{p}=0.004$; $\mathrm{PM} 2, \mathrm{p}=0.01$, and $\mathrm{M} 1, \mathrm{p}=0.005)$. Distance between the inter-central fossa of the first molars increased to a statistically significant degree (M1-ICF, $\mathrm{p}=0.002$ ). The inter-apical dimension for the cuspids and second premolars increased, while for the first premolars and molars decreased, but none to a statistically significant degree. Arch length increase also was not statistically significant.

\section{Conventional cases}

In order to determine the changes from the initial measurements to the final measurements of the conventional cases, a paired $t$-test was performed for each respective tooth's IOD, ICF, IAD, and arch length.

Maxilla: All inter-occlusal measurements (K9, PM1, PM2, and M1) increased during treatment. However, there were only statistically significant differences in the inter-occlusal arch width for the first premolars (PM1, $\mathrm{p}=0.017$ ). The inter-central fossa measurements between the first molars increased slightly during treatment but not to a significant degree. The inter-apical measurements increased slightly in all measured teeth except for the first molar which decreased slightly, with only the first premolars approaching statistical significance $(\mathrm{p}=0.06)$. Arch length increased, but not to a statistically significant degree (Table 2).

Mandible: All inter-occlusal arch widths (K9, PM1, PM2 and M1) increased during treatment, with statistically significant changes only in the cuspids (K9, $\mathrm{p}=0.045)$ and second premolars (PM2, $\mathrm{p}=0.031)$ with the molars approaching statistical significance $(\mathrm{M} 1, \mathrm{p}=0.075)$.

\begin{tabular}{|c|c|c|c|c|c|c|c|c|c|c|c|}
\hline \multirow{3}{*}{ Measurement } & \multirow[b]{3}{*}{ Tooth } & \multicolumn{5}{|c|}{ Damon Treatment } & \multicolumn{5}{|c|}{ Conventional Treatment } \\
\hline & & \multirow[b]{2}{*}{ N } & \multirow{2}{*}{$\begin{array}{c}\text { Initial } \\
\text { Mean } \pm \text { SD } \\
(\mathrm{mm})\end{array}$} & \multirow{2}{*}{$\begin{array}{l}\text { Final } \\
\text { Mean } \pm \text { SD } \\
(\mathrm{mm})\end{array}$} & \multirow[b]{2}{*}{$\mathbf{t}$} & \multirow[b]{2}{*}{ p } & \multirow[b]{2}{*}{$\mathbf{N}$} & \multirow{2}{*}{$\begin{array}{c}\text { Initial } \\
\text { Mean } \pm \text { SD } \\
(\mathrm{mm})\end{array}$} & \multirow{2}{*}{$\begin{array}{c}\text { Final } \\
\text { Mean } \pm \text { SD } \\
(\mathrm{mm})\end{array}$} & \multirow[b]{2}{*}{$\mathbf{t}$} & \multirow[b]{2}{*}{ p } \\
\hline & & & & & & & & & & & \\
\hline \multirow{4}{*}{$1 O D^{1}$} & K9 & 5 & $34.6 \pm 2.1$ & $37.1 \pm 2.1$ & 3.53 & $0.024^{*}$ & 5 & $34.7 \pm 4.3$ & $35.3 \pm 3.2$ & 0.548 & 0.613 \\
\hline & PM1 & 5 & $41.3 \pm 2.4$ & $44.8 \pm 2.5$ & 3.688 & $0.021^{*}$ & 5 & $41.0 \pm 3.5$ & $43.1 \pm 2.96$ & 3.908 & $0.017^{*}$ \\
\hline & PM2 & 5 & $47.0 \pm 2.8$ & $49.3 \pm 3.0$ & 3.236 & $0.032^{*}$ & 5 & $46.8 \pm 3.6$ & $48.0 \pm 3.1$ & 1.144 & 0.316 \\
\hline & M1 & 5 & $53.6 \pm 3.0$ & $54.2 \pm 3.2$ & 1.404 & 0.233 & 5 & $54.9 \pm 3.3$ & $55.1 \pm 2.4$ & 0.403 & 0.708 \\
\hline ICF $^{2}$ & M1 & 5 & $46.2 \pm 2.5$ & $47.4 \pm 3.2$ & 3.466 & $0.026^{*}$ & 5 & $47.8 \pm 3.0$ & $47.9 \pm 3.5$ & 0.204 & 0.849 \\
\hline \multirow{4}{*}{$I A D^{3}$} & K9 & 5 & $29.0 \pm 2.4$ & $28.5 \pm 2.7$ & 0.695 & 0.525 & 5 & $29.4 \pm 3.8$ & $29.96 \pm 3.3$ & 0.543 & 0.616 \\
\hline & PM1 & 5 & $36.9 \pm 2.8$ & $36.1 \pm 1.7$ & 0.911 & 0.414 & 5 & $33.6 \pm 4.4$ & $36.9 \pm 3.3$ & 2.597 & 0.06 \\
\hline & PM2 & 5 & $36.9 \pm 2.2$ & $36.2 \pm 2.8$ & 1.389 & 0.237 & 5 & $39.2 \pm 2.9$ & $40.3 \pm 3.5$ & 1.705 & 0.163 \\
\hline & M1 & 5 & $30.5 \pm 2.9$ & $28.5 \pm 3.9$ & 1.097 & 0.334 & 5 & $35.8 \pm 8.7$ & $34.3 \pm 5.3$ & 0.871 & 0.433 \\
\hline $\mathrm{AL}^{4}$ & & 5 & $30.7 \pm 0.8$ & $32.4 \pm 1.8$ & 2.356 & 0.078 & 5 & $31.8 \pm 4.7$ & $33.1 \pm 5.2$ & 1.212 & 0.292 \\
\hline
\end{tabular}

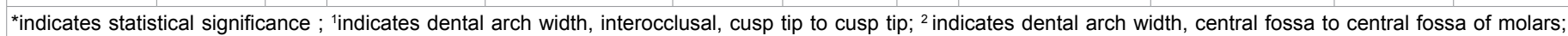
${ }^{3}$ indicates dental arch width, interapical, root tip to root tip; ${ }^{4}$ indicates arch length.

Table 2: Damon and conventional maxillary arch measurements ( $\mathrm{mm}$ ) before and after treatment; inter-occlusal arch dimension (IOD), first molar inter-central fossa (ICF), inter-apical dimension (IAD), and arch length $(A L)$. 


\begin{tabular}{|c|c|c|c|c|c|c|c|c|c|c|c|}
\hline \multirow{3}{*}{ Measurement } & \multirow[b]{3}{*}{ Tooth } & \multicolumn{5}{|c|}{ Damon Treatment } & \multicolumn{5}{|c|}{ Conventional Treatment } \\
\hline & & \multirow[b]{2}{*}{$\mathbf{N}$} & \multirow{2}{*}{$\begin{array}{c}\text { Initial } \\
\text { Mean } \pm \text { SD } \\
(\mathrm{mm})\end{array}$} & \multirow{2}{*}{$\begin{array}{c}\text { Final } \\
\text { Mean } \pm \text { SD } \\
(\mathrm{mm})\end{array}$} & \multirow[b]{2}{*}{$\mathbf{t}$} & \multirow[b]{2}{*}{$\mathbf{p}$} & \multirow[b]{2}{*}{$\mathbf{N}$} & \multirow{2}{*}{$\begin{array}{c}\text { Initial } \\
\text { Mean } \pm \text { SD } \\
(\mathrm{mm})\end{array}$} & \multirow{2}{*}{$\begin{array}{c}\text { Final } \\
\text { Mean } \pm \text { SD } \\
(\mathrm{mm})\end{array}$} & \multirow[b]{2}{*}{$\mathbf{t}$} & \multirow[b]{2}{*}{$\mathbf{p}$} \\
\hline & & & & & & & & & & & \\
\hline \multirow{4}{*}{$\mathrm{IOD}^{1}$} & K9 & 5 & $22.5 \pm 3.7$ & $27.6 \pm 5.8$ & 2.752 & $0.040^{*}$ & 5 & $25.3 \pm 3.3$ & $28.3 \pm 3.5$ & 2.881 & $0.045^{*}$ \\
\hline & PM1 & 5 & $24.9 \pm 2.7$ & $30.2 \pm 2.5$ & 5.061 & $0.004^{*}$ & 5 & $26.6 \pm 6.3$ & $27.2 \pm 3.3$ & 0.299 & 0.780 \\
\hline & PM2 & 5 & $29.2 \pm 3.5$ & $32.9 \pm 2.2$ & 4.006 & $0.010^{*}$ & 5 & $31.0 \pm 3.6$ & $32.5 \pm 2.7$ & 3.251 & $0.031^{*}$ \\
\hline & M1 & 5 & $33.5 \pm 3.1$ & $36.1 \pm 3.2$ & 4.671 & $0.005^{*}$ & 5 & $34.8 \pm 3.7$ & $35.5 \pm 3.5$ & 2.390 & 0.075 \\
\hline $\mathrm{ICF}^{2}$ & M1 & 5 & $41.7 \pm 3.4$ & $44.5 \pm 3.4$ & 6.031 & $0.002^{*}$ & 5 & $42.8 \pm 3.5$ & $43.3 \pm 3.8$ & 2.390 & 0.075 \\
\hline \multirow{4}{*}{$I A D^{3}$} & K9 & 5 & $24.5 \pm 3.3$ & $24.9 \pm 2.5$ & 0.564 & 0.597 & 5 & $22.0 \pm 1.1$ & $24.3 \pm 0.9$ & 3.438 & $0.026^{*}$ \\
\hline & PM1 & 5 & $33.4 \pm 3.1$ & $32.2 \pm 2.5$ & 1.537 & 0.185 & 5 & $32.9 \pm 4.1$ & $32.4 \pm 3.2$ & 0.769 & 0.485 \\
\hline & PM2 & 5 & $40.5 \pm 2.2$ & $41.4 \pm 3.2$ & 1.519 & 0.189 & 5 & $41.9 \pm 3.8$ & $41.7 \pm 3.5$ & 0.425 & 0.692 \\
\hline & M1 & 5 & $49.8 \pm 4.3$ & $48.7 \pm 3.4$ & 0.836 & 0.441 & 5 & $49.0 \pm 3.3$ & $50.5 \pm 4.4$ & 1.517 & 0.204 \\
\hline $\mathrm{AL}^{4}$ & & 5 & $21.6 \pm 1.2$ & $22.3 \pm 1.8$ & 1.755 & 0.140 & 5 & $23.7 \pm 6.5$ & $24.1 \pm 2.2$ & 0.150 & 0.888 \\
\hline
\end{tabular}

* indicates statistical significance ; ${ }^{1}$ indicates dental arch width, interocclusal, cusp tip to cusp tip; ${ }^{2}$ indicates dental arch width, central fossa to central fossa of molars; ${ }^{3}$ indicates dental arch width, interapical, root tip to root tip; ${ }^{4}$ indicates arch length.

Table 3: Damon and conventional mandibular arch measurements $(\mathrm{mm})$ before and after treatment; inter-occlusal arch dimension (IOD), first molar inter-central fossa (ICF), inter-apical dimension (IAD), and arch length (AL).

The first molars inter-central fossa measurements increased slightly, but not to a statistically significant degree. The inter-apical distance of the first molars and cuspids both increased, however only the cuspids were statistically significant $(p=0.026)$. Both first and second premolars inter-apical distances decreased, but not significantly. Arch length increased, however not to a statistically significant degree (Table 3 ).

\section{Damon treatment changes versus conventional treatment changes}

Maxilla: In the maxilla, the inter-occlusal arch width (IOD) increase of the Damon treated group for cuspids and premolars was larger, approaching significance $(\mathrm{K} 9, \mathrm{p}=0.10$; $\mathrm{PMs}, \mathrm{p}=0.10)$. Statistical analysis showed a significant increase in the combined changes for inter-occlusal arch widths during treatment for the Damon versus the Conventional treated cases $(\mathrm{p}=0.025)$. The changes in the first molars inter-central fossa widths (M1-ICF) of the Damon group approached significance, with a greater change in the Damon group $(\mathrm{p}=0.10)$. The maxillary inter-apical distances however, had increased significantly more in the Conventional treated cases as opposed to the Damon treated cases in premolars, whether they were examined individually (PM1, $\mathrm{p}=0.025 ; \mathrm{PM} 2, \mathrm{p}=0.05$ ) or combined as a group $(\mathrm{PMs}, \mathrm{p}=0.005)$. There was also a significantly greater increase in the second premolars and the combined premolars' buccal alveolar crest distances (PM2, $\mathrm{p}=0.01$; PMs, $\mathrm{p}=0.005$ ) versus greater change in the lingual alveolar crest distances (ILACD) in the maxilla of the Conventional treated cases $(\mathrm{p}=0.05$ ). The only significant difference in the measured distances for the first molars was an increase in the lingual plates of bone in the Conventional cases $(\mathrm{p}=0.05)$ (Table 4$)$.

Mandible: The Damon cases exhibited a significantly greater increase in inter-occlusal arch dimension for the premolars when measured individually ( $\mathrm{PM} 1, \mathrm{p}=0.025$; $\mathrm{PM} 2, \mathrm{p}=0.05$ ) and when the measurements were combined (PMs, $\mathrm{p}=0.005$ ), and for the first molars $(p=0.025)$. The increase in inter-central fossa of the first molars was also significantly greater in the Damon group $(\mathrm{p}=0.005)$. There was also a significantly greater change in the overall inter-occlusal arch width changes during treatment in the Damon cases as opposed to the Conventional cases $(p=0.001)$. The only significant change between the two treatments in the inter-apical dimension was between the cuspids, with a greater increase for the Conventional cases $(p=0.025)$; however, the second premolar and first molar approached significance. The second premolar in the Damon treated group had the greater change, while the first molar had the greater change in the Conventional group. The inter-buccal alveolar crest dimension (IBACD) of the first premolar was greater in the Conventional group than the Damon group. The lingual alveolar crest accompanying the Conventional cuspid teeth also increased respectively, $(\mathrm{p}=0.05)$. For all other measured teeth there was a significantly greater increase in ILACD in the Damon treated cases as opposed to the Conventional cases (PM1, $\mathrm{p}=0.05 ; \mathrm{PM} 2, \mathrm{p}=0.005$; M1, $\mathrm{p}=0.01)$. Although arch length increased in both treatment groups in both arches with slightly more increase in the Damon group, there was no statistically significant difference between the two groups (Tables 4 and 5).

No statistically significant difference was observed between the different $\mathrm{CBCT}$ views (3D coordinate system, coronal section, and volume) for inter-occlusal arch width measurements for the combined maxilla and mandible (Table 6) or for the inter-occlusal arch width measurements for the maxilla and mandible separately (Table 7).

The ratios of overall arch expansion between the groups were measured and the ratios of crown versus root movement were examined. At the crown level in the maxilla, the Damon system resulted in 2.2 (2.2:1) times more arch expansion than the Conventional system, $(\mathrm{p}=0.05)$. In the mandible, the Damon system resulted in $2.8(4.2: 1.5)$ times more arch expansion than the Conventional system, $(\mathrm{p}=0.01)$ (Table 8). For the maxillary dentition in the Damon group the ratio of crown to root movement was 3.2:1, while in the Conventional group the ratio was 1:0.7, $(\mathrm{p}=0.01)$ (Table 9). For the mandibular dentition, the apical distances increased more in the Conventional system as opposed to the Damon system in all teeth, but significantly more in the cuspids and molars. The ratio of crown to root movement for the Damon group was 5.9:1 versus 2.6:1 in the Conventional group, $(\mathrm{p}=0.01)$ (Table 10).

\section{Discussion}

When a claim is made about the effects of one mechanics system as a way of promoting that system over another, then it becomes necessary to compare the effects of the two systems. If the Damon system is purported to promote 'arch development' in a different or more effective way than the Conventional system, then it is important to analyze the differences between the two systems. If both the Conventional and Damon system resolve crowding by virtue of the same biologic mechanism, then one cannot claim superiority. If however, some important differences exist, then those differences need to be quantified so that informed decision-making can be made regarding treatment options. The two 
Citation: Askari M, Williams R, Romberg E, Stone M, Alexander SA (2015) CBCT Assessment of Dental and Skeletal Changes Using the Damon versus Conventional (MBT) System. Dentistry 5: 336. doi:10.4172/2161-1122.1000336

\begin{tabular}{|c|c|c|c|c|c|c|}
\hline Tooth & Measurement & $\mathbf{N}$ & $\begin{array}{c}\text { Damon } \\
\text { (Mean } \pm \text { SD) }\end{array}$ & $\begin{array}{c}\text { Conventional (Mean } \\
\pm \text { SD) }\end{array}$ & $\mathbf{t}$ & $\begin{array}{c}p \\
\text { (1-tailed) }\end{array}$ \\
\hline \multirow{5}{*}{ K9 } & $\mathrm{IOD}^{1}$ & $10(5,5)$ & $2.5 \pm 1.6$ & $0.5 \pm 2.2$ & 1.611 & 0.10 \\
\hline & $I A D^{2}$ & $10(5,5)$ & $-0.5 \pm 1.5$ & $0.5 \pm 2.2$ & 0.843 & 0.40 \\
\hline & $\mathrm{IBACD}^{3}$ & $10(5,5)$ & $-1.1 \pm 2.5$ & $-2.6 \pm 1.7$ & 1.088 & 0.25 \\
\hline & ILACD 4 & $10(5,5)$ & $1.1 \pm 1.3$ & $1.2 \pm 2.0$ & 0.021 & 0.99 \\
\hline & $\mathrm{R} / \mathrm{L}$-angle ${ }^{5}$ & $20(10,10)$ & $3.5 \pm 16.4^{\circ}$ & $3.3 \pm 8.2^{\circ}$ & 0.029 & 0.99 \\
\hline \multirow{5}{*}{ PM1 } & IOD & $10(5,5)$ & $3.5 \pm 2.1$ & $2.0 \pm 1.2$ & 1.352 & 0.25 \\
\hline & IAD & $10(5,5)$ & $-0.8 \pm 1.9$ & $3.3 \pm 2.8$ & 2.667 & $0.025^{*}$ \\
\hline & IBACD & $10(5,5)$ & $2.8 \pm 3.2$ & $0.8 \pm 1.5$ & 1.298 & 0.25 \\
\hline & ILACD & $10(5,5)$ & $2.3 \pm 2.7$ & $1.0 \pm 1.2$ & 0.990 & 0.25 \\
\hline & R/L-angle & $20(10,10)$ & $3.0 \pm 10.8^{\circ}$ & $-3.5 \pm 12.1^{\circ}$ & 1.253 & 0.25 \\
\hline \multirow{5}{*}{ PM2 } & IOD & $10(5,5)$ & $2.3 \pm 1.6$ & $1.2 \pm 2.4$ & 0.833 & 0.25 \\
\hline & IAD & $10(5,5)$ & $-0.69 \pm 1.1$ & $1.1 \pm 1.4$ & 2.199 & $0.05^{*}$ \\
\hline & IBACD & $10(5,5)$ & $1.9 \pm 2.9$ & $0.1 \pm 0.5$ & 3.308 & $0.01^{*}$ \\
\hline & ILACD & $10(5,5)$ & $1.3 \pm 1.3$ & $1.0 \pm 1.3$ & 0.331 & 0.40 \\
\hline & R/L-angle & $20(10,10)$ & $1.7 \pm 12.4^{\circ}$ & $-0.1 \pm 12.5^{\circ}$ & 0.320 & 0.40 \\
\hline \multirow{6}{*}{ M1 } & IOD & $10(5,5)$ & $0.6 \pm 1.0$ & $0.23 \pm 1.3$ & 0.548 & 0.40 \\
\hline & ICF & $10(5,5)$ & $1.2 \pm 0.8$ & $0.2 \pm 1.4$ & 1.455 & 0.10 \\
\hline & IAD & $10(5,5)$ & $-1.9 \pm 3.9$ & $-1.6 \pm 4.1$ & 0.126 & 0.25 \\
\hline & IBACD & $10(5,5)$ & $0.1 \pm 1.4$ & $-0.2 \pm 2.0$ & 0.285 & 0.40 \\
\hline & ILACD & $10(5,5)$ & $-1.5 \pm 2.2$ & $0.7 \pm 1.3$ & 1.914 & $0.05^{*}$ \\
\hline & R/L-angle & $20(10,10)$ & $2.3 \pm 6.6^{\circ}$ & $3.5 \pm 5.4^{\circ}$ & 0.442 & 0.40 \\
\hline \multirow{5}{*}{ PM1 \& PM2 } & IOD & $20(10,10)$ & $2.9 \pm 1.9$ & $1.6 \pm 1.8$ & 1.530 & 0.10 \\
\hline & IAD & $20(10,10)$ & $-0.7 \pm 1.5$ & $2.2 \pm 2.4$ & 3.272 & $0.005^{*}$ \\
\hline & IBACD & $20(10,10)$ & $2.9 \pm 2.5$ & $0.4 \pm 1.1$ & 2.878 & $0.005^{*}$ \\
\hline & ILACD & $20(10,10)$ & $0.3 \pm 1.92$ & $2.1 \pm 2.4$ & 1.967 & $0.05^{\star}$ \\
\hline & $\mathrm{R} / \mathrm{L}$-angle & $40(20,20)$ & $2.3 \pm 11.4^{\circ}$ & $-1.8 \pm 12.1^{\circ}$ & 1.107 & 0.25 \\
\hline All Teeth & IOD & $40(20,20)$ & $2.2 \pm 1.8$ & $1.0 \pm 1.8$ & 2.107 & $0.025^{*}$ \\
\hline \multicolumn{2}{|c|}{ Arch Length ${ }^{6}$} & $10(5,5)$ & $1.7 \pm 1.6$ & $1.2 \pm 2.3$ & 0.408 & 0.40 \\
\hline
\end{tabular}

Table 4: Comparison of the combined maxillary arch changes (final-initial) in mm or degrees between the Damon versus conventional systems.

\begin{tabular}{|c|c|c|c|c|c|c|}
\hline Tooth & Measurement & $\mathbf{N}$ & $\begin{array}{c}\text { Damon } \\
(\text { Mean } \pm \text { SD) }\end{array}$ & $\begin{array}{c}\text { Conventional (Mean } \\
\pm \text { SD) }\end{array}$ & $\mathbf{t}$ & $\underset{\text { (1-tailed) }}{p}$ \\
\hline \multirow{5}{*}{ K9 } & $\mathrm{IOD}^{1}$ & $11(6,5)$ & $5.1 \pm 4.5$ & $3.0 \pm 2.3$ & 0.934 & 0.25 \\
\hline & $I A D^{2}$ & $11(6,5)$ & $0.4 \pm 1.8$ & $2.6 \pm 1.3$ & 2.306 & $0.025^{*}$ \\
\hline & $\mathrm{IBACD}^{3}$ & $11(6,5)$ & $-0.8 \pm 2.7$ & $-2.5 \pm 4.2$ & 0.841 & 0.25 \\
\hline & ILACD 4 & $11(6,5)$ & $0.3 \pm 1.8$ & $2.0 \pm 0.8$ & 1.864 & $0.05^{*}$ \\
\hline & $\mathrm{R} / \mathrm{L}$-angle ${ }^{5}$ & $22(12,10)$ & $0.4 \pm 9.9$ & $4.9 \pm 10.4$ & 1.043 & 0.25 \\
\hline \multirow{5}{*}{ PM1 } & IOD & $11(6,5)$ & $5.4 \pm 2.6$ & $0.6 \pm 4.2$ & 2.335 & $0.025^{*}$ \\
\hline & IAD & $11(6,5)$ & $-1.2 \pm 1.9$ & $-0.5 \pm 1.5$ & 0.624 & 0.40 \\
\hline & IBACD & $11(6,5)$ & $0.4 \pm 2.0$ & $0.6 \pm 0.9$ & 0.178 & 0.10 \\
\hline & ILACD & $11(6,5)$ & $2.0 \pm 1.4$ & $0.3 \pm 1.3$ & 2.076 & $0.05^{*}$ \\
\hline & R/L-angle & $22(12,10)$ & $6.1 \pm 10.0$ & $4.5 \pm 8.5$ & 0.424 & 0.40 \\
\hline \multirow{5}{*}{ PM2 } & IOD & $11(6,5)$ & $3.7 \pm 2.3$ & $1.5 \pm 1.0$ & 1.998 & $0.05^{\star}$ \\
\hline & IAD & $11(6,5)$ & $0.9 \pm 1.5$ & $-0.2 \pm 1.1$ & 1.410 & 0.10 \\
\hline & IBACD & $11(6,5)$ & $2.3 \pm 1.5$ & $1.3 \pm 1.8$ & 1.022 & 0.25 \\
\hline & ILACD & $11(6,5)$ & $2.1 \pm 1.3$ & $-0.5 \pm 1.0$ & 3.640 & $0.005^{*}$ \\
\hline & R/L-angle & $22(12,10)$ & $6.1 \pm 9.5$ & $0.5 \pm 10.0$ & 1.348 & 0.10 \\
\hline \multirow{6}{*}{ M1 } & IOD & $11(6,5)$ & $2.6 \pm 1.4$ & $0.7 \pm 0.7$ & 2.745 & $0.025^{*}$ \\
\hline & ICF & $11(6,5)$ & $2.8 \pm 1.1$ & $0.4 \pm 0.8$ & 3.921 & $0.005^{*}$ \\
\hline & IAD & $11(6,5)$ & $-1.1 \pm 3.1$ & $1.5 \pm 2.2$ & 1.533 & 0.10 \\
\hline & IBACD & $11(6,5)$ & $1.5 \pm 0.9$ & $0.6 \pm 1.7$ & 1.021 & 0.25 \\
\hline & ILACD & $11(6,5)$ & $1.5 \pm 1.1$ & $-0.1 \pm 0.4$ & 2.918 & $.0 .01^{*}$ \\
\hline & R/L-angle & $22(12,10)$ & $5.9 \pm 5.7$ & $4.3 \pm 6.2$ & 0.634 & 0.40 \\
\hline \multirow{5}{*}{ PM1 \& PM2 } & IOD & $22(12,10)$ & $4.5 \pm 2.4$ & $1.0 \pm 2.9$ & 3.012 & $0.005^{*}$ \\
\hline & IAD & $22(12,10)$ & $-0.1 \pm 1.9$ & $-0.4 \pm 1.2$ & 0.314 & 0.40 \\
\hline & IBACD & $22(12,10)$ & $1.4 \pm 2.0$ & $0.9 \pm 1.4$ & 0.560 & 0.40 \\
\hline & ILACD & $22(12,10)$ & $2.0 \pm 1.3$ & $-0.1 \pm 1.2$ & 4.065 & $0.001^{*}$ \\
\hline & R/L-angle & $44(24,20)$ & $6.2 \pm 9.5$ & $2.5 \pm 9.3$ & 1.282 & 0.25 \\
\hline All Teeth & IOD & $44(24,20)$ & $4.2 \pm 2.9$ & $1.5 \pm 2.5$ & 3.270 & $0.001^{*}$ \\
\hline \multicolumn{2}{|c|}{ Arch Length 6} & $11(6,5)$ & $0.7 \pm 0.9$ & $0.3 \pm 4.8$ & 0.176 & 0.99 \\
\hline
\end{tabular}

*indicates statistical significance; ${ }^{1}$ indicates dental arch width; interocclusal cusp tip to cusp tip; ${ }^{2}$ indicates dental arch width; interapical, root tip to root tip; ${ }^{3}$ indicates skeletal arch width; buccal crest to buccal crest; ${ }^{4}$ indicates skeletal arch width; lingual crest to lingual crest; ${ }^{5}$ indicates the angle between cusp tip and nasal floor; ${ }^{6}$ indicates arch length.

Table 5: Comparison of the combined mandibular arch changes (final-initial) in mm or degrees between the Damon versus conventional systems. 
Citation: Askari M, Williams R, Romberg E, Stone M, Alexander SA (2015) CBCT Assessment of Dental and Skeletal Changes Using the Damon versus Conventional (MBT) System. Dentistry 5: 336. doi:10.4172/2161-1122.1000336

Page 8 of 10

\begin{tabular}{|c|c|c|c|c|c|c|c|}
\hline \multicolumn{8}{|c|}{ IOD (Dental arch width) for combined arches } \\
\hline \multirow{5}{*}{ Maxilla \& Mandible } & \multirow{2}{*}{ Tooth } & \multirow{2}{*}{$\mathbf{N}$} & \multicolumn{3}{|c|}{ View (Mean \pm SD) } & \multirow{2}{*}{$\mathbf{F}$} & \multirow{2}{*}{ p-value } \\
\hline & & & Sectional & Volume & 3D & & \\
\hline & K9 & $126(42,42,42)$ & $29.5 \pm 5.8$ & $30.8 \pm 5.2$ & $30.2 \pm 6.1$ & 0.607 & 0.547 \\
\hline & PM2 & $126(42,42,42)$ & $39.1 \pm 8.9$ & $39.4 \pm 9.3$ & $39.2 \pm 8.9$ & 0.013 & 0.987 \\
\hline & M1 & $126(42,42,42)$ & $44.3 \pm 10.5$ & $44.3 \pm 10.7$ & $44.2 \pm 10.3$ & 0.001 & 0.999 \\
\hline
\end{tabular}

Table 6: ANOVA comparison of inter-occlusal arch width measurements $(\mathrm{mm})$ via the sectional, volume and 3D views of CBCT for combined maxilla and mandible.

\begin{tabular}{|c|c|c|c|c|c|c|c|}
\hline \multicolumn{8}{|c|}{ IOD (Dental arch width) for Maxilla and Mandible } \\
\hline \multirow{6}{*}{ Maxilla } & \multirow{2}{*}{ Tooth } & \multirow{2}{*}{$\mathbf{N}$} & \multicolumn{3}{|c|}{ View (Mean \pm SD) } & \multirow{2}{*}{$\mathbf{F}$} & \multirow{2}{*}{ p-value } \\
\hline & & & Sectional & Volume & 3D & & \\
\hline & K9 & $60(20,20,20)$ & $34.4 \pm 3.3$ & $35.5 \pm 2.6$ & $35.0 \pm 2.9$ & 0.651 & 0.525 \\
\hline & PM1 & $60(20,20,20)$ & $42.4 \pm 2.96$ & $43.3 \pm 2.8$ & $42.6 \pm 3.1$ & 0.553 & 0.578 \\
\hline & PM2 & $60(20,20,20)$ & $47.7 \pm 3.09$ & $48.5 \pm 3.0$ & $47.3 \pm 3.1$ & 0.792 & 0.458 \\
\hline & M1 & $60(20,20,20)$ & $54.7 \pm 3.4$ & $54.9 \pm 3.3$ & $54.4 \pm 2.8$ & 0.792 & 0.908 \\
\hline \multirow{3}{*}{ Mandible } & K9 & $66(22,22,22)$ & $24.98 \pm 3.3$ & $26.6 \pm 2.97$ & $25.8 \pm 3.7$ & 1.103 & 0.338 \\
\hline & PM2 & $66(22,22,22)$ & $31.2 \pm 3.4$ & $31.1 \pm 3.4$ & $31.3 \pm 3.2$ & 0.024 & 0.976 \\
\hline & M1 & $66(22,22,22)$ & $34.9 \pm 3.4$ & $34.7 \pm 3.5$ & $34.9 \pm 3.3$ & 0.019 & 0.981 \\
\hline
\end{tabular}

Table 7: ANOVA comparison of inter-occlusal arch width measurements $(\mathrm{mm})$ via the sectional, volume and 3D views of CBCT for separate maxilla and mandible.

\begin{tabular}{|c|c|c|c|}
\hline & \multicolumn{3}{|c|}{ Overall Arch Expansion } \\
\hline & Damon & Conventional & 1.0 \\
\hline Maxilla & 2.2 & $0.05^{*}$ & 1.5 \\
\hline Mandible & 4.2 & $0.01^{*}$ \\
\hline *indicates a statistical significance & & \\
\hline
\end{tabular}

Table 8: Comparison of overall arch expansion $(\mathrm{mm})$ during treatment in the Damon and conventional treated cases.

\begin{tabular}{|c|c|c|c|c|c|c|c|}
\hline \multirow{2}{*}{ Teeth } & \multicolumn{3}{|c|}{ Damon } & \multicolumn{3}{|c|}{ Conventional } & \multirow{2}{*}{ p-value } \\
\hline & $I^{\prime O D}{ }^{1}$ & $I A D^{2}$ & IOD/IAD 3 & IOD & IAD & IOD/IAD & \\
\hline K9 & 2.5 & -0.5 & 5 & 0.5 & 0.5 & 1 & \\
\hline PM1 & 3.5 & -0.8 & 4.3 & 2 & 2.3 & 0.6 & \\
\hline PM2 & 2.3 & -0.69 & 3.3 & 1.2 & 1.1 & 1.09 & \\
\hline M1 & 0.6 & -1.9 & 0.3 & 0.23 & -1.6 & 0.14 & \\
\hline Total & & & 12.9 & & & 2.83 & \\
\hline Total/4 tooth types & & & $3.2 / 1$ & & & $1 / 0.7$ & $0.01^{*}$ \\
\hline
\end{tabular}

*Indicates statistical significance; ${ }^{1}$ indicates dental arch width, interocclusal, cusp tip to cusp tip; ${ }^{2}$ indicates dental arch width, interapical, root tip to root tip; ${ }^{3}$ indicates the ratio between movement of the cusps versus the roots

Table 9: Ratio of maxillary changes in crown to root movement ( $\mathrm{mm})$.

\begin{tabular}{|c|c|c|c|c|c|c|}
\hline \multirow{2}{*}{ Teeth } & \multicolumn{3}{|c|}{ Damon } & \multicolumn{3}{c|}{ Conventional } \\
\cline { 2 - 6 } & IOD $^{1}$ & IAD $^{2}$ & IOD/IAD & IOD & IAD \\
\hline K9 & 5.1 & 0.4 & 12.75 & 3.0 & 2.6 \\
\hline PM1 & 5.4 & -1.2 & 4.5 & 0.6 & -0.5 \\
\hline PM2 & 3.7 & 0.9 & 4.1 & 1.5 & -0.2 \\
\hline M1 & 2.6 & -1.1 & 2.36 & 1.2 & 1.5 \\
\hline Total & & & 23.7 & 0.7 & 0.46 \\
\hline Total/4 tooth types & & $5.9 / 1$ & & 10.31 \\
\hline
\end{tabular}

${ }^{*}$ Indicates statistical significance; ${ }^{1}$ indicates dental arch width, interocclusal, cusp tip to cusp tip; ${ }^{2}$ indicates dental arch width, interapical, root tip to root tip; ${ }^{3}$ indicates the ratio between movement of the cusps versus the roots

Table 10: Ratio of mandibular changes in crown to root movement $(\mathrm{mm})$.

systems in this study were evaluated individually, and then changes during treatment were compared. As a pilot study, the sample size is too small to draw specific and definite conclusions; however, the study is still capable of indicating a pattern of development between the two systems, and therefore has the potential to study these systems in a larger scale. Additionally, when both bracket and wire systems differ during treatment as do the Damon and Conventional appliances, the comparison of effects for both systems may be compounded and difficult to interpret, yet a clinical relationship may be observed.

The results of this study show that non-extraction treatment, utilizing both treatment modalities resulted in inter-occlusal expansion in both arches. These increases were statistically and clinically significant in almost all measurements of maxilla and mandible for the Damon treated cases. For the maxilla in these cases, the significant changes range from the smallest at M1-ICF $(1.2 \mathrm{~mm})$ to the greatest change at PM1 $(3.5 \mathrm{~mm})$. For the mandible, the significant increases ranged from the smallest for M1 $(2.6 \mathrm{~mm})$ to the largest at PM1 $(5.4$ $\mathrm{mm})$. One would expect similar changes in the IOD and ICF when measuring the first molar width. This was not the case in M1-IOD of the maxilla in the Damon group: the M1-IOD increase of $0.6 \mathrm{~mm}$ 
was not statistically significant, while M1-ICF increase of $1.2 \mathrm{~mm}$ was significant. This could be due to measurement error; however this also could have resulted from the buccolingual tip of the molars. This can be further explained by the decrease in the M1-IAD $(1.9 \mathrm{~mm})$, while there was an increase in occlusal arch width.

For the Conventional treated cases, only the occlusal arch width increase in the maxillary PM1 and the mandibular K9 and PM2 proved to be significant with the mandibular M1 increase approaching significance. For the maxilla, these measurements were narrowest, but non-significant at the canine $(0.5 \mathrm{~mm})$ and widest at the first premolar $(2.0 \mathrm{~mm})$. In the mandible, the least amount of expansion occurred at the first molar when measured at the central fossa $(0.4 \mathrm{~mm})$, followed by the PM1 $(0.6 \mathrm{~mm})$, and was largest at the canine $(3.0 \mathrm{~mm})$. These findings are in agreement with those of Gianelly who found increases in inter-premolar and intra-molar widths of non-extraction cases ranging from 0.81-2.10 $\mathrm{mm}$ [6]. The Gianelly study measured arch widths from cusp tips of the canines, premolars, and molars on dental casts of randomly selected extraction and non-extraction cases [6]. As a result, the root positions were not measured and therefore evaluation of expansion due to tipping or bodily movement of the respective teeth could not be determined. Weinberg and Sadowsky in their examination of multimodality non-extraction treatment found that expansion was greatest at the second premolars $(1.8 \mathrm{~mm})$ and least at the canines $(0.9$ $\mathrm{mm}$ ) [8]. The present study indicates the greatest expansion was at PM1. In the lower arch of the Conventional cases however, the greatest increase was in the K9, followed by PM2, while the least expansion in both the Conventional and Damon cases were in the M1 areas of both arches.

In order to differentiate increases in arch width due to bodily versus tipping movements, evaluation of apical displacement must be made. Mah et al. has indicated that CBCTs are of great value in this regard [18]. The results of the inter-apical distance changes from initial to final treatment indicated that Damon cases resulted in decreased IAD for all measured teeth in the maxilla (from $-1.9 \mathrm{~mm}$ at $\mathrm{M} 1$ to 0.05 $\mathrm{mm}$ at $\mathrm{K} 9$ ), with mixed results in the mandible (from $-1.2 \mathrm{~mm}$ at PM1 to $0.9 \mathrm{~mm}$ at PM2). None of these changes were significant. For the Damon group, since the inter-apical distances decreased or remained stationery and the inter-occlusal measurements increased, the arch width increase in the maxilla and mandible occurred with a tipping movement and not translation. This is due to differences in occlusal displacement of the involved teeth moving laterally, with no change or a slight decrease in the corresponding intra-apical areas. Conversely, all inter-apical distances in the maxilla of Conventional cases increased slightly (from $0.5 \mathrm{~mm}$ at $\mathrm{K} 9$ to $3.3 \mathrm{~mm}$ at PM1) with the exception of a slight decrease $(-1.6 \mathrm{~mm})$ in the M1-IAD. There were mixed results in the mandible however, with the greatest decrease at PM1 $(0.5 \mathrm{~mm})$ and the greatest increase at the $\mathrm{K} 9(2.6 \mathrm{~mm})$. The only significant change for the inter-apical distance was an increase in the mandibular canine of the Conventional group. An examination of the crown and root movements indicated that for the Conventional treatment in the maxilla and mandible, there were bodily movements for the maxillary PM1 and mandibular K9. The mandibular PM2 and M1, on the other hand had significantly more IOD expansion than IAD, indicating tipping of these teeth. The movement in the remaining teeth did not have significant IAD/IOD changes, indicating a mixture of changes with no specific pattern of tipping or bodily movement, whereas in the Damon cases expansion occurred via tipping of the crowns of the teeth.

Arch length in the maxilla and mandible increased for both the Conventional (maxilla: $1.2 \mathrm{~mm}$, mandible: $0.3 \mathrm{~mm}$ ) and Damon (maxilla: $1.7 \mathrm{~mm}$, mandible: $0.7 \mathrm{~mm}$ ) groups with changes in the maxilla of the Damon group approaching significance. The study therefore, does not support the claim that in Damon treated cases there is less tipping of the incisors as compared to Conventional cases $[13,14,22]$.

The results of this study indicate that in the maxilla there was no statistically significant difference between the treatment groups in arch width (IOD) for the teeth measured individually; however, when looked at as a group, the statistical analysis showed significantly larger differences in the Damon cases when compared to the Conventional cases for the combined change in arch width for both arches. This indicated significantly greater overall arch expansion in the Damon group during treatment both in the maxilla and in the mandible. In the mandible, there was a significantly greater increase in the occlusal arch dimension for premolars both when measured individually and when the values were combined. This was also true for the molars. The premolar inter-apical distances, however, increased significantly more in the maxilla of the Conventional cases as opposed to the Damon cases, whether they were looked at individually or combined as a group. This indicated that there was more bodily movement of the premolars in the maxilla of the Conventional cases. For the mandible, neither treatment category displayed this result.

In the mandible of the Conventional cases, there were no significant changes in the lingual plates of bone. The only significant increase was in the buccal plate of the first premolars. In the maxilla, there were significant increases in the lingual plates of first and second premolars and molars, but no significant increases in the buccal plates. No specific pattern was observed. For the Damon cases, all lingual plates increased significantly, which was not so for the buccal plates. In the maxilla, there was no significant change in ther lingual plates, but significant changes in the buccal plates for the second premolars and combined premolars. This does not support the Damon claim that "as the arch is developed", the buccal and lingual bones are carried with it.

The mixed results in the mandible as opposed to the maxilla can be due to the inherent differences in the bone morphology and physiology between the respective jaws. The results of the IBACD and ILACD might also be explained by volume averaging. Since these areas are the contact points between teeth and alveolar bone, the CBCT machines may not be able to distinguish these points as clearly as one would expect. This can result in a misreading of data, and why the Damon assertion is not supported. Additionally, since the resolution of CBCT at $0.2 \mathrm{~mm}$ voxel, less than $1 \mathrm{~mm}$ of bone may not be seen [23]; therefore to distinguish bone remodeling of either the buccal or lingual plates, actual changes in these areas with the Damon or Conventional systems may be inaccurately measured.

To better understand the mode with which teeth moved during arch expansion, the ratios of overall arch expansion between the Damon and Conventional group were examined. To see the manner in which teeth moved, the ratios of crown versus root movement were studied. Arch expansion at the crown level for the Damon group in the maxilla was 2.2 times greater, while approximately three times greater in the mandible when compared to the Conventional system. This interocclusal arch expansion however, is via bucco-lingual tipping of the teeth and not bodily movement, with the crowns in the Damon group moving three times as much as their apices. Although arch expansion was greater in the Damon treated cases as opposed to the Conventional cases, this was at the expense of greater tipping.

No significant differences in arch length was observed between the groups, yet overall arch length increased for both groups; the 
resolution of crowding therefore, was not only through the mechanism of expansion, but also arch length increase in both systems. Since the angulations of the incisors to their respective basal bone was not measured in this study, one cannot determine with certainty whether the arch length increase was due to molar distalization and not the labial movement of the incisors, which would be more likely to occur.

It has been advocated that the Damon philosophy is similar to what was described by Angle 100 years ago with the only difference being in the armamentarium used [15]. Damon uses resilient coppernickel-titanium alloys that produce expansion forces much gentler than Angle's gold, German silver, or chrome steel. The Damon bracket is also essentially a tube when compared to a conventional bracket. The shortcomings of this study when comparing Damon versus Conventional treatment are in the small sample size observed and arch wire placement durations that fell short of the suggested timelines. Nevertheless, the clinically and statistically significant difference observed between the two methods of treatment indicate that the resolution of crowding utilizing the Damon system is gained by crown tipping and not bone growth of the maxilla and mandible as have been advocated. Future studies may incorporate the use of study casts for precise measurements of crowding and also for determining the results of the treatment. CBCTs with patients not in intercuspation for better reading of occlusal indices may also be used. Since no statistically significant difference was observed between the different CBCT views, the clinician can be fairly confident of the accuracy of the CBCT measurements of the inter-occlusal arch widths and lengths in any of the views.

\section{Conclusions}

With the results of the study we can conclude that arch length in the maxilla and mandible increased for both the Conventional and Damon groups, but without statistical differences between the groups. Both the treatment groups exhibited arch width expansion in both maxilla and mandible, with the Damon group significantly greater than the Conventional group. Arch expansion was statistically and clinically significant in the majority of maxillary and mandibular measurements for the Damon group while the Conventional group only showed a statistically significant difference during treatment for the maxillary PM1 and mandibular K9 and PM2. The greatest expansion achieved was at the PM1 site in both treatment groups. The ratio of the crown to root movement for the Conventional group in the maxilla was approximately 1:1, versus 3:1 for the Damon group. The ratio of the crown to root movement for the Conventional group in the mandible was 3.6:1, versus 6:1 in the Damon group. No statistically significant difference was observed between the three different views in $\mathrm{CBCT}$, therefore the coordination of an image in all three planes of space may not be necessary for simple measurements.

\section{Acknowledgement}

We gratefully acknowledge the cases provided by Dr. David Paquette, Dr. Ty Saini, and Dr. Raj Saini for use in this study and Dr. Dov Elman and Dr. Jeffrey Gardyn, $3^{\text {rd }}$ year dental students who participated in data measurement at the University of Maryland, Maryland, United States.

\section{References}

1. Berkovitz BKB, Holland GR, Moxham BJ (1984) A Colour Atlas and Textbook of Oral Anatomy. Wolfe, London.
2. Bowman SJ, Johnston LE Jr (2000) The esthetic impact of extraction and nonextraction treatments on Caucasian patients. Angle Orthod 70: 3-10.

3. Erdinc AE, Nanda RS, Dandajena TC (2007) Profile changes of patients treated with and without premolar extractions. Am J Orthod Dentofacial Orthop 132: $324-331$

4. Işiksal E, Hazar S, Akyalçin S (2006) Smile esthetics: perception and comparison of treated and untreated smiles. Am J Orthod Detofacial Orthop 129: 8-16.

5. Johnson DK, Smith RJ (1995) Smile esthetics after orthodontic treatment with and without extraction of four first premolars. Am J Orthod Dentofacial Orthop 108: $162-167$.

6. Gianelly AA (2003) Arch width after extraction and nonextraction treatment. Am J Orthod Dentofacial Orthop 123: 25-28.

7. Brandt S, Tweed CH (1967) JCO interviews Dr. Charles H. Tweed. J Clin Orthod 1: 142-148.

8. Weinberg M, Sadowsky C (1996) Resolution of mandibular arch crowding in growing patients with Class I malocclusions treated nonextraction. Am J Orthod Dentofac Orthop 110: 359-364.

9. Bergersen EO (1972) A cephalometric study of the clinical use of the mandibular labial bumper. Am J Orthod 61: 578-602.

10. Cetlin NM, Ten Hoeve A (1983) Nonextraction treatment. J Clin Orthod 17: 396-413.

11. Wertz R, Dreskin M (1977) Midpalatal suture opening: a normative study. Am J Orthod 71: 367-381.

12. Sandstom RA, Klapper L, Papaconstantinou S (1988) Expansion of the lower arch concurrent with rapid maxillary expansion. Am J Orthod Dentofac Orthop 94: 296-302.

13. Damon DH (1998) The Damon low friction bracket: a biologically compatible straight wire system. J Clin Orthod 32: 670-680.

14. Damon $\mathrm{DH}$ (1998) The rationale, evolution and clinical application of selfligating bracket. Clin Ortho Res 1: 52-61.

15. Peck S (2008) What's new? Arch expansion again. Angle Orthod 78: 574-575

16. Vajaria R, BeGole E, Kusnoto B, Galang MT, Obrez A (2011) Evaluation of incisor and dental transverse dimension changes using the Damon system. Angle Orthod 81: 647-652.

17. Pandis N, Polychronopoulou A, Eliades T (2007) Self-ligating vs. conventiona brackets in the treatment of mandibular crowding: a prospective clinical trial of treatment duration and dental effects. Am J Orthod Dentofacial Orthop 132 208-215.

18. Mah JK, Huang JC, Choo HR (2010) Practical applications of cone-beam computed tomography in orthodontics. J Am Dent Assoc 141: 7S-13S

19. Hernandez-Soler V, Enciso R, Cisneros GJ (2011) The virtual patient specificmodel and the virtual dental model. Sem Orthod 17: 46-48.

20. Dahlberg G (1940) Statistical methods for medical and biological students Interscience Publications, New York.

21. Damstra J, Fourie Z, Huddleston Slater JJR, Ren Y (2011) Reliability and the smallest detectable difference of measurements on 3-dimensional cone- beam computed tomography images. Am J Orthod Dentofac Orthop 140: e107-e114.

22. Damon DH (2005) Treatment of the face with biocompatible orthodontics Graber LW, Vanarsdall RL Jr, Vig KWL (eds). In: Orthodontics: Current Principles and Techniques. ( $4^{\text {th }}$ edn), Elsevier Mosby, St. Louis.

23. Patcas R, Müller L, Ullrich O, Peltomäki T (2012) Accuracy of cone-beam computed tomography at different resolutions assessed on the bony covering of the mandibular anterior teeth. Am J Orthod Dentofac Orthop 141: 41-50. 